\title{
Yellow fever vaccination and neurological complications
}

\author{
Taciana de Souza Bayão[1], Marli do Carmo Cupertino ${ }^{[1],[2],}$ \\ Andréia Patrícia Gomes ${ }^{[1]}$ and Rodrigo Siqueira-Batista ${ }^{[1],[2]}$
}

\author{
[1]. Laboratório de Métodos Epidemiológicos e Computacionais em Saúde, \\ Departamento de Medicina e Enfermagem, Universidade Federal de Viçosa, Viçosa, MG, Brasil. \\ [2]. Escola de Medicina, Faculdade Dinâmica do Vale do Piranga, Ponte Nova, MG, Brasil.
}

Yellow fever, as other arboviruses, has reemerged as an important public health problem in Brazil ${ }^{1,2}$. Until April 19, 2018, the Brazilian Ministry of Health had confirmed more than 1,150 cases of this disease in the country, in which 340 of these cases evolved to death. For infection prevention and control, a yellow fever vaccine (YFV) has been shown as being highly effective. It is also a safe immunobiological agent, consisting of an attenuated virus of the 17DD sub-strain, promoting immunization in $90-98 \%$ of vaccinated people ${ }^{1}$. Approximately 17.8 million people were vaccinated against yellow fever in the Bahia, Rio de Janeiro, and São Paulo States, most of them with fractioned doses, until March 2018. In addition, at the time of circulation of the virus in several regions of Brazil, the Ministry of Health aimed at gradual vaccination throughout the national territory, targeting 77.5 million people vaccinated by $2019^{3}$.

The YFV in a standard or fractionated dose is quite safe to induce seroconversion in previously seronegative individuals, although adverse effects may occur, which in rare cases could lead to serious changes, including neurological disorders and eventual death. Studies indicate that the occurrence of serious adverse effects related to the YFV in Brazil between 2007 and 2012 was 0.42 cases per 100,000 doses, and the incidence of neurological adversities [yellow fever vaccineassociated neurologic disease (YEL-AND)] in the country was 0.20 per 100,000 doses. In addition, in cases of booster doses, assessments released by the World Health Organization indicate low incidence rates of YEL-AND, although they require more detailed and comparative studies of primo-vaccinated individuals. In this sense, the YEL-AND cases described in the literature are not unfeasible vaccination campaigns; they are rare and usually have a good prognosis. However, it is important that the doctor, especially the neurologist, is aware of the main adverse effects involving the central and peripheral nervous systems post-vaccination, given the proportions that the current vaccination campaign has achieved in the country. Thus, the purpose of this communication is to present a brief

Corresponding author: Rodrigo Siqueira-Batista e-mail: rsiqueirabatista@yahoo.com.br

Receveid 20 July 2018

Accepted 30 July 2018 summary of the clinical neurological conditions that may occur in individuals who have received the YFV.

In the neurological diseases group associated with the 17DD YFV, cases of acute infections and autoimmune reactions are included. Among the meningoencephalic syndromes described, clinical signs such as fever, seizure and/or meningism were observed on average one to three weeks after vaccination, usually with a brief course and frequently with full recovery. In these cases, to determine them as definitive, an important criterion was the presence of specific immunoglobulin M (IgM) against the virus in the cerebrospinal fluid $(\mathrm{CSF})^{4,5}$. Other diseases involving the central nervous system described in YEL-ANDs, although still rarer, are acute disseminated encephalomyelitis, transverse myelitis, and bilateral optic neuromyelitis ${ }^{4}$.

In the YEL-AND cases triggered by autoimmune mechanisms, the diagnostic investigation involved the association between the CSF biochemical analysis standard and clinical evidence of demyelination with negativity for any other causal disease agents, other than the vaccine ${ }^{4}$, given that in these cases, there were no specific laboratory evaluations available to verify the YFV as the cause. On the other hand, in these same autoimmune neurological disorders, the absence of CSF-specific IgM antibodies is not conclusive to deny a possible effect of the vaccine. Thus, although suspect or probable cases need more thorough study, they deserve to be recognized. Reports of neurological deficits and electrophysiological data characteristic of Guillain-Barré syndrome in the post-vaccination period, for example, may help in the search for better diagnostic methods for YEL-AND, although some cases cannot be declared as definitive ${ }^{4}$.

In this sense, neurotropism due to the YFV does not justify the reduction in the current vaccination campaigns, since besides the rarity of the cases, there is a great chance of good prognosis. However, in the face of a clinical condition that raises suspicion of the diseases already described, investigation of the vaccine history in the medical interview is an extremely relevant strategy for the diagnosis.

\section{Acknowledgments}

This study was supported by the Conselho Nacional de Desenvolvimento Científico e Tecnológico $(\mathrm{CNPq}$ - National Council for Scientific and Technological Development) and the Research Program of the Faculdade Dinâmica do Vale do Piranga (PROAPP/FADIP). 


\section{Conflict of interest}

The authors declare that there is no conflict of interest.

\section{REFERENCES}

1. Ministério da Saúde (MS). Secretaria de Vigilância em Saúde. Febre amarela: Guia para Profissionais de Saúde. $4^{\text {th }}$ edição. Brasília: MS; 2017. $67 \mathrm{p}$

2. Puccioni-sohler M, Roveroni N, Rosadas C, Ferry F, Peralta JM, Tanuri A. Dengue infection in the nervous system: lessons learned for Zika and Chikungunya. Arq Neuro-Psiquiatr. 2017;75(2):123-6.
3. Ministério da Saúde (MS). Situação Epidemiológica no Brasil. Vacina de febre amarela será ampliada para todo o Brasil. Brasília: MS; 2018. Citado: 01 abr 2018. Disponível em: http://portalms.saude. gov.br/noticias/agencia-saude/42849-vacina-de-febre-amarela-seraampliada-para-todo-o-brasil

4. McMahon AW, Eidex RB, Marfin AA, Russell M, Sejvar JJ, Markoff L, et al. Neurologic disease associated with 17D-204 yellow fever vaccination: A report of 15 cases. Vaccine. 2007;25(10):1727-34.

5. Fernandes GC, Camacho LA, Sá Carvalho M, Batista M, de Almeida SM. Neurological adverse events temporally associated to mass vaccination against yellow fever in Juiz de Fora, Brazil, 19992005. Vaccine. 2007;25(16):3124-8. 